\title{
Calculation of Effective Earth Radius and Point Refractivity Gradient in UAE
}

\author{
Abdulhadi Abu-Almal and Kifah Al-Ansari \\ Electrical Engineering Department, Ajman University of Science and Technology, Al-Jurf, P.O. Box 346 Ajman, UAE \\ Correspondence should be addressed to Kifah Al-Ansari, anac.kifah@ajman.ac.ae \\ Received 1 April 2010; Accepted 21 May 2010 \\ Academic Editor: Tat Yeo \\ Copyright () 2010 A. Abu-Almal and K. Al-Ansari. This is an open access article distributed under the Creative Commons \\ Attribution License, which permits unrestricted use, distribution, and reproduction in any medium, provided the original work is \\ properly cited.

\begin{abstract}
A large set of 14 years of reliable local radiosonde meteorological data, from 1990 to 2003, has been used to calculate the effective Earth radius and point refractivity gradient in the United Arab Emirates. The obtained values are used to investigate their impact on the design of microwave links. The cumulative distribution of the refractivity gradient in the first 65 meters above the ground surface, the monthly distribution for the median value of the $k$-factor, as well as their comparison with the ITU-maps are provided. Both experimental and global standard values are applied to specific link budget calculations.
\end{abstract}

\section{Introduction}

Radio waves may bend while propagating through different atmospheric layers due to variations of refractivity. These variations are determined by meteorological conditions, mainly temperature and humidity, which are strongly varying with the geographical location and time of the year. The whole Gulf region is likely to experience anomalous propagation due to its special climate. In this regard, few studies are available for this region. This work has been conducted for the coastal city of Abu Dhabi that is located at $24.52^{\circ} \mathrm{N}$ latitude and $54.98^{\circ} \mathrm{E}$ longitudes, with an altitude of $27 \mathrm{~m}$ above sea level. The climate is hot and humid most of the year.

For microwave link design, some parameters such as the effective earth radius factor, $k$, and the point refractivity gradient, $\mathrm{d} N_{1}$, must be set carefully to optimize its performance. Both the $k$-factor, which is directly related to the vertical gradient of refractivity, and $\mathrm{d} N_{1}$ need to be calculated correctly [1]. Commonly, the $k$-factor is set as a standard value of $4 / 3$, and estimated values of $d N_{1}$ are provided by ITU tables for different geographical locations wherever reliable local data are not available [2]. In this paper, long-term experimental radiosounding data, registered in two daily ascents, 0 and 12 hours, have been used to calculate the above values and compare them with the proposed ITU values.
1.1. Effective Earth Radius. It is the radius of a hypothetical spherical Earth, without atmosphere, for which propagation paths follow straight lines, the heights and ground distances being the same as for the actual Earth in an atmosphere with a constant vertical gradient of refractivity [3].

The $k$-factor can be derived from the vertical refractivity gradient, $\Delta N$, in the first kilometer above the ground. It is obtained from two refractivity values, $N_{s}$, surface refractivity, and $N_{1}$, refractivity at $1 \mathrm{~km}$ height above the ground. Since data at exact heights are not available, the following equation is used [4]:

$$
\Delta N=\frac{N_{s}-N_{1}}{h_{s}-h_{1}},
$$

where $h_{1}$ is the point nearest to $1 \mathrm{~km}$ height and $\Delta N$ is calculated only if $900 \mathrm{~m}<h_{1}<1100 \mathrm{~m}$. The statistical analyses of surface refractivity and first kilometer refractivity gradient in Abu Dhabi have been discussed previously in [5].

The $k$-factor can be calculated from Snell's law in spherical geometry $[3,6]$. This value must be multiplied by the actual Earth's radius, $a$, in order to plot the propagation paths as straight lines, as follows:

$$
k=\frac{1}{(1+a(d n / d h))},
$$


where $a$ is usually given in nautical miles, nmi, rather than kilometers, $\mathrm{km}(a=6371 \mathrm{~km}=3440 \mathrm{nmi})$, and $d n / d h$ is the rate of change of the refractive index with height, knowing that $N=(n-1) \times 10^{6}$.

Alternatively, the median $k$-factor may also be calculated using the median $\Delta N$ as follows [1]:

$$
k=\frac{157}{157-\Delta N} \text {. }
$$

1.2. Point Refractivity Gradient. The vertical refractivity gradient in the lowest 100 meters of the troposphere above the ground is an important parameter to estimate propagation effects such as ducting, surface reflection, and multipath on terrestrial line-of-sight links. $\mathrm{d} N_{1}$ is the point refractivity gradient in the lowest $65 \mathrm{~m}$ of the atmosphere not exceeded for $1 \%$ of an average year $[2,7]$. The $\mathrm{d} N_{1}$ value is obtained using (1), where $N_{1}$ is calculated considering the $h_{1}$ value nearest to $65 \mathrm{~m}$ height, so that $60 \mathrm{~m}<h_{1}<70 \mathrm{~m}$.

\section{Results and Analysis}

2.1. $k$-Factor. The refractivity gradient for the first kilometer has been calculated for fourteen years in Abu Dhabi city. The values have been found to vary between -200 and $63 \mathrm{~N} / \mathrm{km}$ [5]. The long-term median value of $\Delta N$ has also been derived yielding a value equal to $-71.3 \mathrm{~N} / \mathrm{km}$, while the global standard value is $-40 \mathrm{~N} / \mathrm{km} \mathrm{[6].} \mathrm{Accordingly,} \mathrm{using}$ (3), a $k$-factor value of 1.83 has been obtained, while its global standard value is $4 / 3$ [6], with an absolute difference of 0.5 .

The monthly distribution of median $\Delta N$ has been calculated, showing variations from -47 to $-107 \mathrm{~N} / \mathrm{km}$. These values, using (3), produce the corresponding $k$-factor distribution as shown in Figure 1. It must be noted that the experimental $k$-factor presents a large variability from 1.43 to 3.17 which is always above $4 / 3$. The highest values correspond to the summer months of June and July. The $k$ factor value, 3.18, might be considered in some conditions as the worst case; otherwise the long-term median value should be used taking into account the probability of link outage during summer time.

2.2. Point Refractivity Gradient. Figure 2 shows the cumulative distribution of the refractivity gradient at $65 \mathrm{~m}$ height from the ground in Abu Dhabi. The value of $\mathrm{d} N_{1}$ not exceeded for $1 \%$ of the time for the full measurement period is $-1029 \mathrm{~N} / \mathrm{km}$. The obtained gradient values for different time percentages in comparison with ITU maps are given in Table 1. Bilinear interpolation has been used to get exact values of $\Delta N$ from the maps for the site coordinates. The results are in good agreement with the ITU values for the percentages of $1 \%$ and $50 \%$. Some differences are observed which might otherwise be attributed to the high variability and abnormality of the climatic parameters of the region.

2.3. Microwave Link Budget Analysis. The values obtained for both parameters have been investigated using a specialized software-planning tool to find out their impact on the

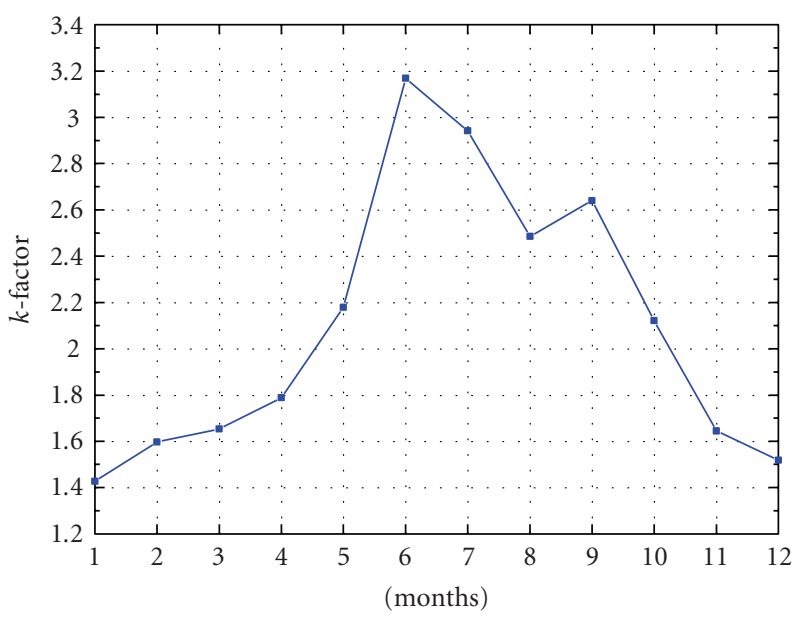

Figure 1: Monthly distribution of median $k$-factor.

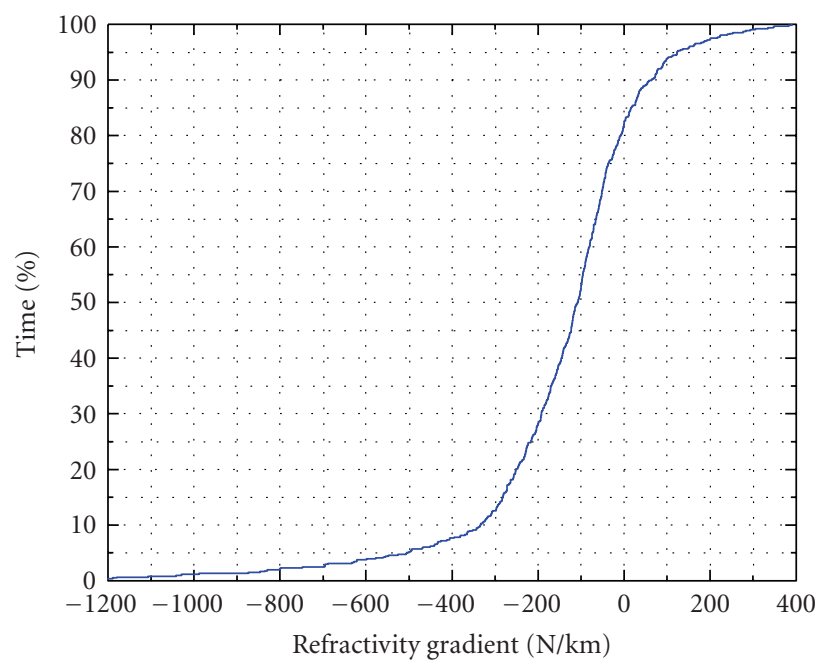

FIgure 2: Cumulative distribution of the refractivity gradient at $65 \mathrm{~m}$.

TABLE 1: Values of $d N$ not exceeded for different time percentages compared with ITU maps.

\begin{tabular}{lcc}
\hline Time percentage & ITU values $(\mathrm{N} / \mathrm{km})$ & Obtained values $(\mathrm{N} / \mathrm{km})$ \\
\hline $1 \%$ & -952.42 & -1029 \\
$10 \%$ & -553 & -333.5 \\
$50 \%$ & -92.824 & -108 \\
$90 \%$ & -4.38 & 63.6 \\
$99 \%$ & 38.86 & 293.6 \\
\hline
\end{tabular}

microwave link performance [8]. A significant number of links, operating within the microwave network of UAE along the coastal line of the Gulf including Abu Dhabi, have been considered for this test. Results for two point-to-point microwave links currently in operation in a region with relatively flat terrain without buildings are presented below.

Figure 3 shows the path profile of a microwave link with two antenna heights of $27 \mathrm{~m}$ and $15 \mathrm{~m}$ above the ground, at 


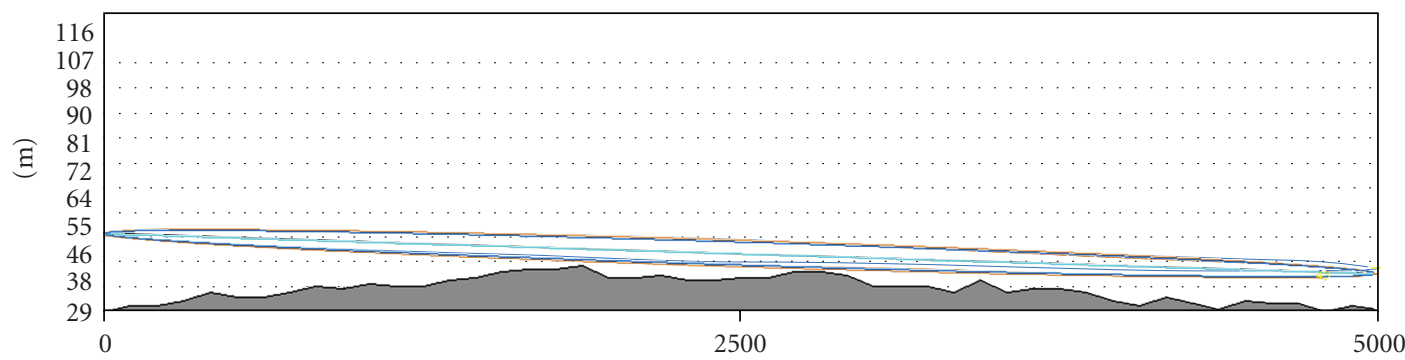

(m)

Site A:

[Tx] polarization: $\mathrm{V}$

Altitude: $29 \mathrm{~m}$

Coordinates: 55.252524 .99642

Antenna height: $27 \mathrm{~m}$
Site B:

$[\mathrm{Rx}]$ polarization: $\mathrm{V}$

Altitude: $30 \mathrm{~m}$

55.2058324 .98378

Antenna: $15 \mathrm{~m}$

Effective earth radius (Km): 11660 (land, sea), Path reliability: 99.999\%

Frequency band: $23 \mathrm{GHz}$, Power: $1 \mathrm{dBm},(\mathrm{EIRP}=11.09 \mathrm{dBW})$

FIgURE 3: Microwave link budget, $k=1.83$.

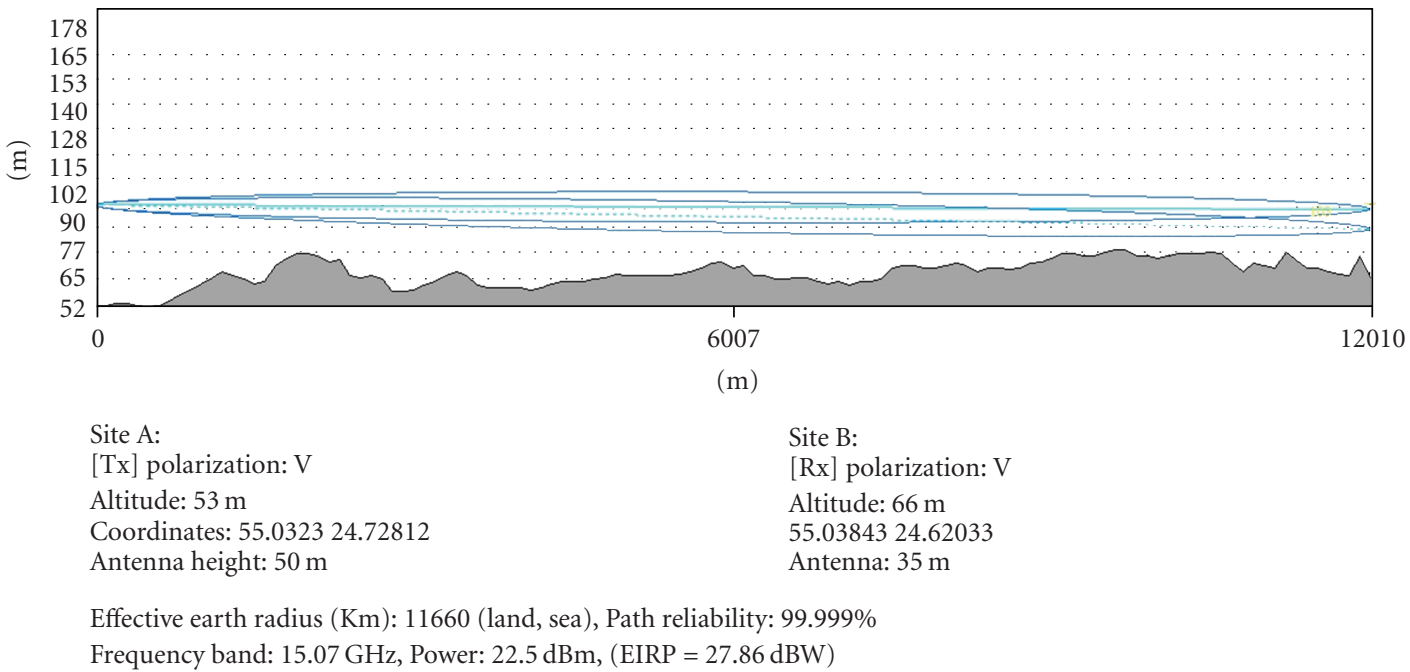

FIGURE 4: Microwave link budget, $\mathrm{d} N_{1}=-1029 \mathrm{~N} / \mathrm{km}$.

sites $\mathrm{A}$ and $\mathrm{B}$, respectively. As discussed above, the median $k$ factor for this region has been found equal to 1.83 , so that the required link availability of $99.999 \%$ is achieved when the antenna minimum height is $15 \mathrm{~m}$ at site $\mathrm{B}$, while antenna height at site A remains fixed. Since the $k$-factor in the region of interest is always above the global value equal to 1.33 , the same availability could not be guaranteed if this value is considered. In other words, microwave link availability would be better with an antenna height of $15 \mathrm{~m}$ and $k$-factor is 1.83 . Table 2 provides the required antenna heights at site B for both $k$ values, to achieve the $99.999 \%$ link availability.

Another microwave link in operation in Abu Dhabi city is considered for studying the impact of changing the $\mathrm{d} N_{1}$ value on the link availability. The sites coordinates and antenna heights for this example are given in Figure 4 . The value of $\mathrm{d} N_{1}$ assigned by the software for the given location was $-1782 \mathrm{~N} / \mathrm{km}$, which is the highest
TABLE 2: MW link availability corresponding to $k$-factor value.

\begin{tabular}{lcc}
\hline$k$-factor value & $\begin{array}{c}\text { Effective Earth } \\
\text { radius }(\mathrm{km})\end{array}$ & $\begin{array}{c}\text { Minimum } \\
\text { Antenna height } \\
\text { for } 99.999 \% \\
\text { Availability }(\mathrm{m})\end{array}$ \\
\hline 1.33 & 8500 & 12 \\
1.83 & 11660 & 15 \\
\hline
\end{tabular}

value in the ITU maps that was adopted by the software. Poor link availability resulted from these values, whereas the link budget calculations improved considerably when the previous $\mathrm{d} N_{1}$ value was substituted with the calculated value of $-1029 \mathrm{~N} / \mathrm{km}$. Values for this case are given in Table 3. 
TABLE 3: Link availability due to global and experimental $d N_{1}$ values.

\begin{tabular}{lc}
\hline $\mathrm{d} N_{1}$ Values $(\mathrm{N} / \mathrm{km})$ & Link Availability $(\%)$ \\
\hline-1782 & 82.2708 \\
-1029 & 99.9989 \\
\hline
\end{tabular}

\section{Conclusions}

In this paper, reliable local radiosonde data collected during a long-time span (14 years) have been used to calculate the effective Earth radius and the point refractivity gradient in Abu Dhabi. Microwave link budget was investigated to find out the impact of both parameters on the microwave link performance. Results of two of these links have been presented as case studies. Calculated results of $k$-factor showed a monthly variation from 1.43 to 3.17 , a span of 1.74 units, with the highest values observed in the summer months. The long-term values were found to be 1.83 as median value for the $k$-factor and $-1029 \mathrm{~N} / \mathrm{km}$ for the $\mathrm{d} N_{1}$. Since the calculations have been done using local data, these values are strongly recommended to be adopted for better microwave link performance and availability in this region. When high values of the two parameters are experienced, increasing the transmitted power and the antenna heights (if possible) may improve the performance. On the other hand, power should be kept within acceptable limits to avoid interferences. Although microwave link path clearance may be achieved with lower height using the $k$-factor global value as 1.33 , this study recommends using the calculated median $k$-factor value of 1.83 for the microwave design to get the required availability.

\section{Acknowledgments}

The authors would like to express their gratefulness to the Emirates Telecommunication Corporation, ETISALAT, for providing the radio network planning software and to the National Centre of Meteorology and Seismology in UAE for providing the meteorological data used in this work. In addition, a special thank for Dr. Ana Benarroch, from the Polytechnic University of Madrid, for her valuable comments, suggestions, and permanent support.

\section{References}

[1] Recommendation ITU-R P.452-12, "Prediction procedure for the evaluation of microwave interference between stations on the surface of the Earth at frequencies above about $0.7 \mathrm{GHz}$," International Telecommunication Union, 2005.

[2] Recommendation ITU-R P.453-9, "The radio refractive index: its formula and refractivity data," International Telecommunication Union, 2003.

[3] M. I. Skolnik, Introduction to Radar Systems, McGraw-Hill, New York, NY, USA, 3rd edition, 2001.

[4] M. A. Dominguez, A. Benarroch, and J. M. Riera, "Refractivity Statistics in Spain: First Results," Tech. Rep. CP52004, COST 255, May 1998.
[5] K. Al-Ansari, A. Abu Al-Mal, and R. Kamel, "Statistical Analysis of Refractivity in UAE," in International Symposium on Rainfall Rate and Radiowave Propagation (ISRR '07), vol. 923, pp. 232247, American Institute of Physics Conference Proceedings, Salem, India, January 2007.

[6] Recommendation ITU-R PN.310-9, "Definitions Of Terms Relating To Propagation In Non-Ionized Media," International Telecommunication Union, 1994.

[7] Recommendation ITU-R P.530-12, "Propagation data and prediction methods required for the design of terrestrial lineof-sight systems," International Telecommunication Union, 2007.

[8] ICS Telecom software planning tool, Version 9.0.9, by ATDI, Advanced Topographic and Development of Images Company. 

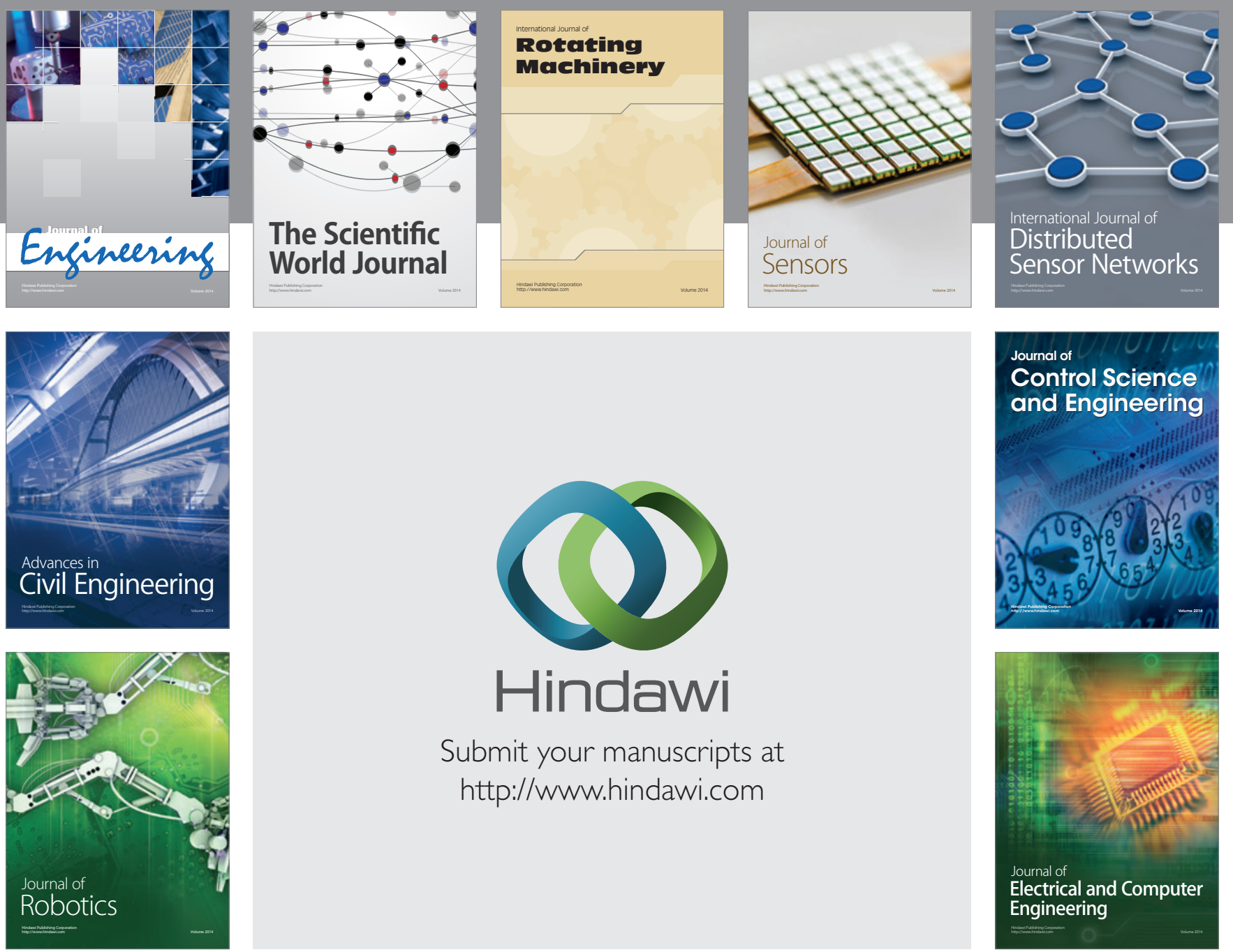

Submit your manuscripts at

http://www.hindawi.com
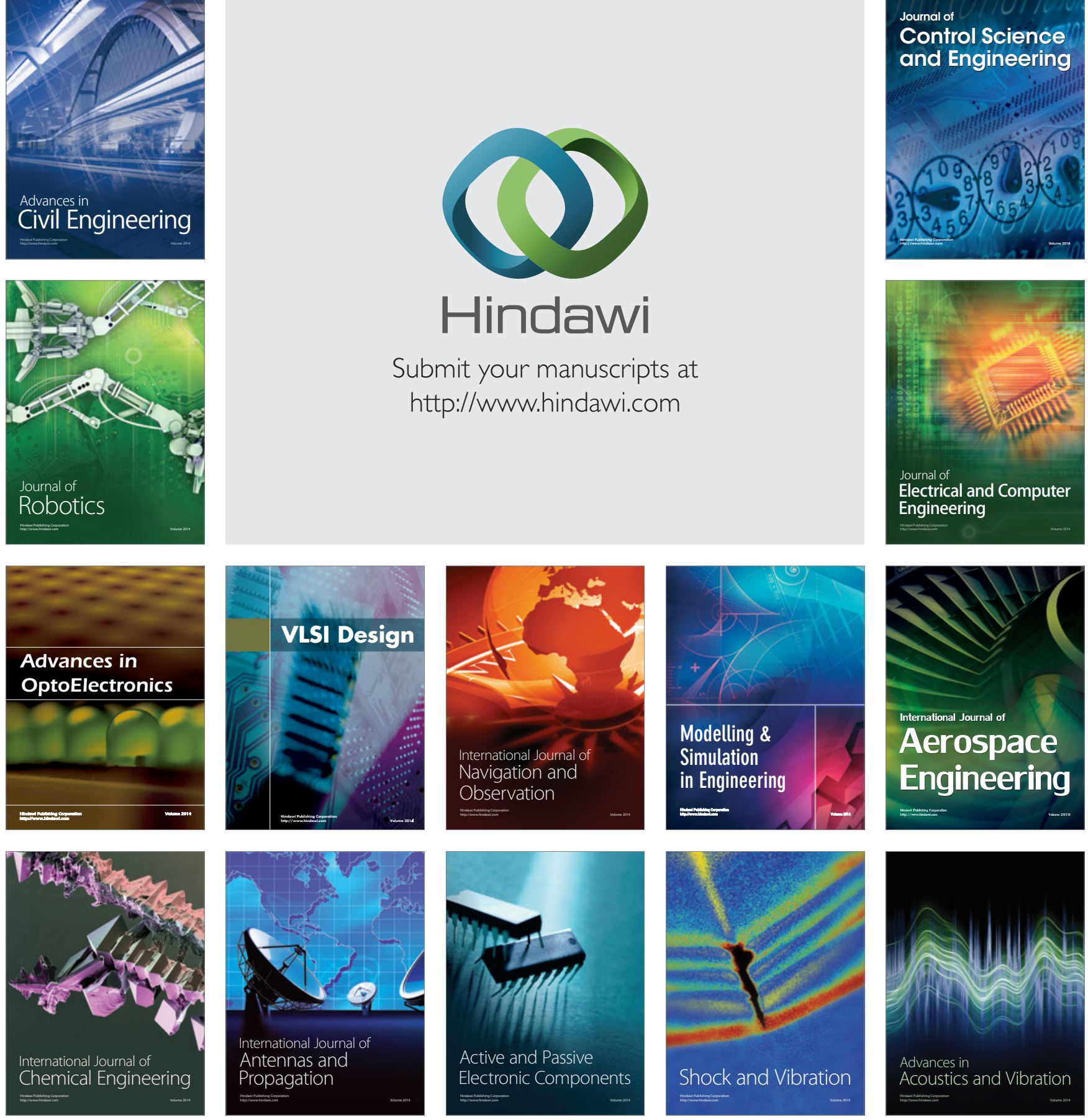